\title{
Incipient plasticity in thin films: an in-situ TEM indentation study
}

\author{
Jeff Th.M. De Hosson, ${ }^{*}$ W.A. Soer, ${ }^{*}$ A.M. Minor, ${ }^{* *}$ Z. Shan, ${ }^{* *}$ S.A. Syed Asif, ${ }^{* * *}$ O.L. Warren ${ }^{* * *}$ \\ * Department of Applied Physics, Materials Science Center and the Netherlands Institute for Metals \\ Research, University of Groningen, Nijenborgh 4, 9747 AG Groningen, The Netherlands \\ ${ }^{* *}$ National Center for Electron Microscopy, Lawrence Berkeley National Laboratory, One Cyclotron \\ Road, MS 72, Berkeley, CA 94720, USA \\ ${ }^{* * *}$ Hysitron Inc., 10025 Valley View Road, Minneapolis, MN 55344, USA
}

Although the microstructure-property relationship is in itself a truism, the actual linkage between structural aspects of dislocations studied by microscopy and mechanical properties is almost elusive. The reason for this is that mechanical properties of metallic systems are determined by the collective and dynamical behavior of dislocations rather than by the behavior of one singular defect. As Cottrell said [1], even before the first observations of dislocations were reported [2,3]: " work hardening was the first problem to be attempted by dislocation theory and may well prove to be the last to be solved". The reason that hampers a straightforward correlation between microscopic observations to mechanical properties is that in the field of dislocations we are facing non-linear and non-equilibrium effects. Cottrell's prediction is still valid but the situation is not hopeless. We argue that for a more quantitative evaluation of the structureproperty relationship extra emphasis on in-situ measurements is necessary. Only recent developments in the field of microscopy, both in transmission and in scanning modes, have made in-situ measurements over various length scales feasible and that will be the topic of this contribution. In particular we will concentrate on in-situ nanoindentation in a transmission electron microscope [4] for direct observation of indentation phenomena of Al-Mg films and the effect of $\mathrm{Mg}$ on the deformation mechanisms [5].

We have conducted in-situ nanoindentation experiments on ultrafine-grained $\mathrm{Al}-\mathrm{Mg}$ films with varying $\mathrm{Mg}$ contents. The observed propagation of dislocations is markedly different between $\mathrm{Al}$ and $\mathrm{Al}-$ $\mathrm{Mg}$ films: the presence of solute $\mathrm{Mg}$ results in solute drag, evidenced by jerky dislocation motion with a mean jump distance that compares well to theoretical and experimental considerations [6]. In fact this solute drag accounts for the difference in load-controlled indentation response between $\mathrm{Al}$ and $\mathrm{Al}-\mathrm{Mg}$ alloys. Several yield excursions are observed during initial indentation of pure Al, which are commonly attributed to collective motion of dislocations nucleated under the indenter. These yield excursions are attenuated during indentation of the Al-Mg alloys, i.e. the solute drag prevents the elastic energy from being released in a sudden dislocation burst and thus smoothes out the initial indentation response. Further, in contrast to highangle grain boundaries, the mobility of low-angle boundaries in Al-Mg was found to be less affected by the presence of $\mathrm{Mg}$. Low-angle grain boundaries were found to be mobile regardless of the $\mathrm{Mg}$ content whereas high-angle grain-boundaries became pinned by $\mathrm{Mg}$.

Opposite to load-controlled experiments, displacement-controlled indentation does not result in a qualitative difference between $\mathrm{Al}$ and $\mathrm{Al}-\mathrm{Mg}$. Displacement-controlled nanoindentation experiments were performed in-situ in a transmission electron microscope using a quantitative indentation stage, which has recently been developed and is described in [7]. The in-situ indentations show a considerable amount of dislocation activity prior to the first macroscopic yield point. While the indented grain is free of dislocations at the onset of loading (Figure 1a), the first dislocations are already nucleated within the first few nanometers of the indentation (Figure 1b), i.e. well before the apparent initial yield point that would be inferred from the load vs. displacement data only. At the inception of the first macroscopic yield event, dislocations are present throughout the entire grain (Figure 1c). The number of newly nucleated dislocations between (c) and 
(d) is relatively small, as also becomes clear from the limited increase in indentation depth (3 nm corresponds to approximately 10 Burgers vectors). This supports our perception that only a small number of dislocations need to be nucleated in order for a yield event to be detected under displacement-controlled conditions [8]. Most interestingly: the yield event itself is associated with a rearrangement of dislocations, which significantly changes the appearance of the dislocation structure (Figure 1d).
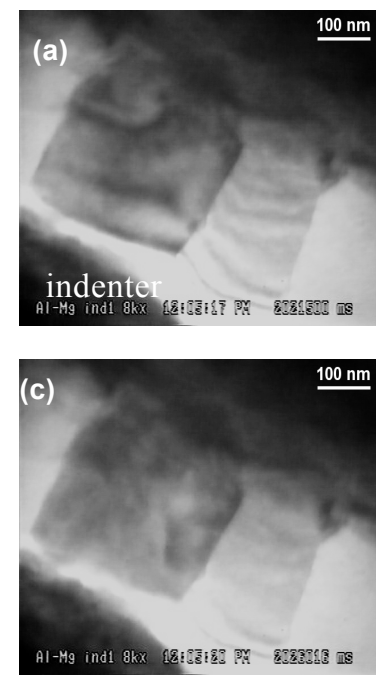

(e)

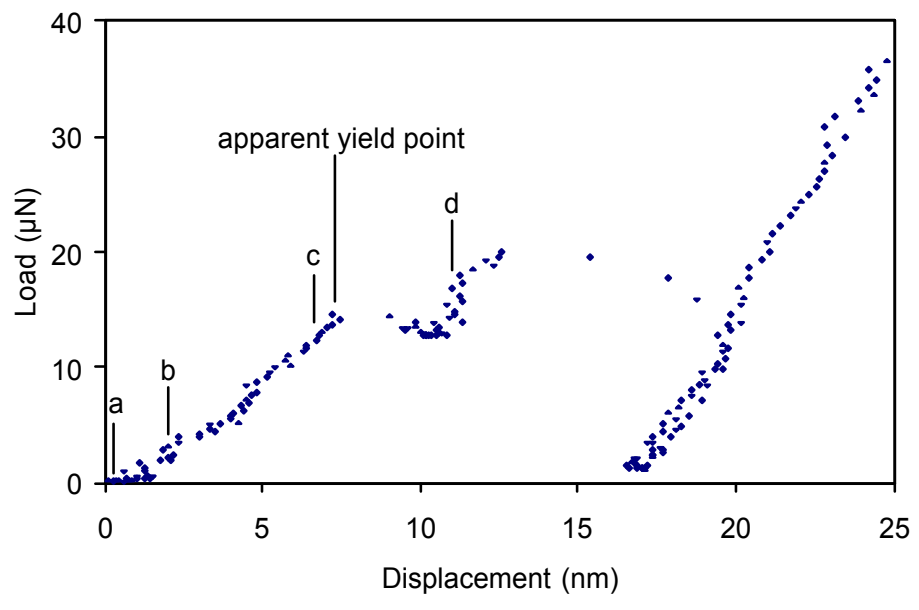

FIG. 1. Image sequence (a-d) from the initial loading portion (e) of the indentation on $\mathrm{Al}-2.6 \% \mathrm{Mg}$. The first dislocations are nucleated between (a) and (b), i.e. prior to the apparent yield point.

\section{References}

[1] A.H. Cottrell, Dislocations and Plastic Flow in Crystals, Clarendon Press, Oxford, 1953.

[2] P.B. Hirsch, R.W. Horne, M.J. Whelan, Phil.Mag. 1(1956) 677.

[3] W. Bollmann, Phys.Rev. 103 (1956) 1588.

[4] E.A. Stach, T. Freeman, A.M. Minor, D.K. Owen, J. Cumings, M.A. Wall, T. Chraska, R. Hull, J.W. Morris, Jr., A. Zettl, U. Dahmen, Microsc. Microanal. 7 (2001), 507.

[5] W.A. Soer, J.Th.M. De Hosson, A.M. Minor, J.W. Morris Jr., E.A. Stach, Acta Mater. 52 (2004), 5783.

[6] J.Th.M. De Hosson, O. Kanert, A.W. Sleeswyk, Dislocations in Solids, Ed. F. R. N. Nabarro, North-Holland-Amsterdam, Vol. 6 (1983) 441-534.

[7] A.M. Minor, Z. Shan, E.A. Stach, S.A. Syed Asif, E. Cyrankowski, T. Wyrobek, O.L. Warren, submitted to Nature.

[8] W.A. Soer, J.Th.M. De Hosson, A.M. Minor, Z. Shan, S.A. Syed Asif, O.L. Warren, in preparation.

[9] This work was funded by the Netherlands Institute for Metals Research under project number MC4.01104. The research was supported in part by a U.S. Department of Energy SBIR grant (DE-FG02-04ER83979) awarded to Hysitron, Inc.. The work at NCEM was supported by the Director, Office of Science, Division of Materials Sciences and Engineering, of the U.S. Department of Energy under Contract No. DE-AC03-76SF00098. 